\title{
Retinol binding protein 4 promotes hyperinsulinism-induced proliferation of rat aortic smooth muscle cells
}

\author{
FEI LI ${ }^{1}$, KE XIA $^{1,2}$, MD SAYED ALI SHEIKH $^{1}$, JINFANG CHENG $^{1}$, \\ CHUANCHANG $\mathrm{LI}^{3}$ and TIANLUN YANG ${ }^{1}$ \\ ${ }^{1}$ Department of Cardiology, Xiangya Hospital, Central South University, Changsha, Hunan 410008, P.R. China; \\ ${ }^{2}$ Center for Vascular Biology and Inflammation, Cardiovascular Division, Department of Medicine, \\ Brigham and Women's Hospital, Harvard Medical School, Boston, MA 02115, USA; \\ ${ }^{3}$ Department of Geriatrics, Xiangya Hospital, Central South University, Changsha, Hunan 410008, P.R. China
}

Received October 11, 2013; Accepted February 20, 2014

DOI: $10.3892 / \mathrm{mmr} .2014 .2028$

\begin{abstract}
Recent studies have suggested that retinol binding protein 4 ( $\mathrm{RBP} 4)$, an adipocytokine related to insulin resistance (IR), may play an important role in the development of atherosclerosis and cardiovascular diseases (CVD). Abnormal proliferation and migration of vascular smooth muscle cells (VSMCs) is one of the most common causes of atherosclerosis. Hyperinsulinism promotes proliferation of VSMCs through the MAPK pathway. However, whether RBP4 is involved in insulin-induced proliferation of VSMCs leading to atherosclerosis remains unclear. In the present study, we evaluated the role of RBP4 and the potential relevance of signaling pathways in this process. Different concentrations of RBP4 (1 and $4 \mu \mathrm{g} / \mathrm{ml}$ ) were added to rat aortic smooth muscle cells (RASMCs) during insulin-induced proliferation. The levels of cell growth signaling pathway proteins ERK1/2, p-ERK1/2, JAK2, p-JAK2, STAT3 and p-STAT3 were assessed by western blotting in order to identify the pathway(s) that are activated during insulin-induced proliferation. The specific inhibitors of ERK1/2 (PD98059) and JAK2 (AG490) were used to confirm our findings. Insulin induced proliferation of RASMCs in a concentration- and time-dependent manner, and increased the expression of ERK1/2, p-ERK1/2, JAK2, p-JAK2, STAT3 and p-STAT3 in a time-dependent manner. RBP4 enhanced insulin-induced proliferation of RASMCs and expression of $\mathrm{p}-\mathrm{ERK} 1 / 2$ and
\end{abstract}

Correspondence to: Dr Tianlun Yang, Department of Cardiology, Xiangya Hospital, Central South University, 87 Xiangya Road, Changsha, Hunan 410008, P.R. China

E-mail: tianluny@163.com

Dr Chuanchang Li, Department of Geriatrics, Xiangya Hospital, Central South University, 110 Xiangya Road, Changsha, Hunan 410008, P.R. China

E-mail: lichuanchan@sina.com

Key words: retinol binding protein 4, hyperinsulinism, vascular smooth muscle cells, proliferation, signaling pathway
p-JAK2. RBP4-induced proliferation of RASMCs was reduced by the ERK1/2 inhibitor, while it was unaffected by the JAK2 inhibitor. These results suggest that RBP4 mediates VSMC proliferation induced by insulin via activation of the MAPK pathway, and highlight RBP4 as a modulator of atherosclerosis in hyperinsulinemia, therby enhancing our understanding on a number of unexpected aspects of CVD.

\section{Introduction}

The endocrine function of adipose tissue has been elucidated in recent years, with the identification of adipocytokines such as leptin, adiponectin and resistin. Adipose tissue produces numerous cytokines and hormones, which act as autocrine, paracrine and endocrine factors and participate in the pathophysiological process of insulin resistance (IR) and chronic inflammation $(1,2)$. Retinol binding protein 4 (RBP4) is an adipocytokine related to IR (3). This was first shown in mice by Yang et al (3), who observed that knockout mice for the gene encoding adipose-specific glucose transporter-4 (GLUT-4) were insulin resistant in muscle and liver, and displayed increased expression of the RBP4 gene. Graham et al (4) subsequently measured the serum RBP4 level, insulin resistance, and components of the metabolic syndrome in lean and obese individuals with or without type 2 diabetes, and found that the serum level of RBP4 correlates with insulin resistance. Additional studies further proved that the level of RBP4 in the blood associates with IR (5-8). IR is followed by compensatory hyperinsulinemia. It is widely accepted that hyperinsulinemia and insulin resistance are the main risk factors of cardiovascular diseases (CVD), eventually leading to the formation and development of atherosclerosis (9).

Vascular smooth muscle cells (VSMCs) have been extensively used to study the pathological mechanisms underlying atherosclerosis. Proliferation and migration of VSMCs is of important value for the formation of coronary atherosclerosis and the development of coronary heart disease (CHD). Insulin is a highly potent cell growth factor, which can promote VSMC proliferation and DNA synthesis, and plays an important role in the formation of atherosclerosis $(10,11)$. Recently, $\mathrm{RBP} 4$, an adipocytokine related to IR, has been suggested to 
play an important role in the occurrence and development of atherosclerosis and CVD (12-14). However, whether RBP4 is involved in insulin-induced proliferation of VSMCs leading to atherosclerosis remains unclear.

Proliferation and migration of VSMCs are related to a variety of signal transduction pathways, such as the mitogen-activated protein kinase (MAPK) and the JAK/ STAT pathway. Insulin activates the MAPK pathway through the Grb2/SOS and RAS proteins to promote cell growth and proliferation, and collagen synthesis (15-17). IR is followed by compensatory hyperinsulinemia, which promotes insulininduced proliferation of VSMCs via the SHC/Raf/MAPK pathway, and accelerates artery atherosclerosis (18). JAK/STAT is another important signal transduction pathway mediating cell proliferation. Binding of cytokines such as interferon, 5-hydroxytryptamine, platelet-derived growth factor and others to the specific receptor activates the protein tyrosine kinase (PTK) Janus kinase (JAK), thereby activating signal transducer and activator of transcription (STAT), and inducing cell proliferation. Previous studies (19-21) have shown that the JAK/STAT signaling pathway plays an important role in VSMC proliferation.

Insulin promotes proliferation of VSMCs to induce formation of atherosclerosis through the MAPK pathway. Ost et al (22) examined the mechanisms of action of RBP4 in primary human adipocytes. RBP4-treated adipocytes displayed the same molecular defects in insulin signaling, mediated by the insulin receptor substrate (IRS) protein 1 and the MAP kinase, as adipocytes from patients with type 2 diabetes. Takebayashi et al (23) further showed that RBP4 has a robust acute effect on the enhancement of NO production via stimulating part of the PI3K/Akt/eNOS pathway and inhibiting insulin-induced ET-1 secretion, probably via the MAPK pathway, eventually causing vasodilatation. However, whether RBP4 is involved in insulin-induced proliferation of VSMCs leading to atherosclerosis remains unclear. In the present study, we evaluated the role of RBP4 in this process and the underlying signaling pathways.

\section{Materials and methods}

Reagents. RBP4 protein was purchased from Sino Biological Inc. (Beijing, China) and was dissolved in a solution comprising sterile $50 \mathrm{mM}$ Tris, $10 \mathrm{mM} \mathrm{CaCl}_{2}$ and $150 \mathrm{mM}$ $\mathrm{NaCl}$ at $\mathrm{pH} 7.5$, at a final concentration of $500 \mu \mathrm{g} / \mathrm{ml}$. Mouse anti-extracellular signal-regulated kinase (ERK)1/2 and -phospho-ERK1/2 (p-ERK1/2) monoclonal antibodies, and rabbit polyclonal anti-JAK2, -p-JAK2, -signal transducer and activator of transcription (STAT) 3 and -p-STAT3 antibodies were purchased from Santa Cruz Biotechnology, Inc. (Santa Cruz, CA, USA). HRP-conjugated goat anti-rabbit and antirat IgGs were purchased from ZSGB-Bio (Beijing, China). The specific inhibitors of ERK1/2 PD098059, and of JAK2 AG490, were purchased from Sigma-Aldrich (St. Louis, MO, USA). Supersignal West Pico Chemiluminescent substrate was purchased from Thermo Scientific (Rockford, IL, USA).

Cell culture. The rat aortic smooth muscle cell (RASMC) line A10 was obtained from the American Type Culture Collection (Manassas, VA, USA). The cells were cultured in Dulbecco's modified Eagle's medium (DMEM) containing 10\% fetal bovine serum (FBS), penicillin $(100 \mathrm{U} / \mathrm{ml})$, streptomycin $(100 \mu \mathrm{g} / \mathrm{ml})$ and $\mathrm{NaHCO}_{3}(3.7 \mathrm{~g} / \mathrm{l})$, in a humidified atmosphere of $5 \% \mathrm{CO}_{2}$ at $37^{\circ} \mathrm{C}$. Cells from passages 7 and 15 were used for the experiments.

Cell proliferation assays. Cell proliferation was analyzed by using the MTT and a cell cycle assay. For the MTT assay, RASMCs were seeded in 96-well plates at a density of $0.6-1.0 \times 10^{4}$ cells/well in DMEM supplemented with $10 \%$ FBS. After $24 \mathrm{~h}$, the medium was replaced with DMEM containing $1 \%$ FBS to render the cells quiescent for $24 \mathrm{~h}$. Then, cells were incubated for different time periods in DMEM containing $1 \%$ FBS and different concentrations of insulin. DMEM containing $1 \%$ FBS and RBP4 (1 or $4 \mu \mathrm{g} / \mathrm{ml})$, PD098059 $\left(5 \times 10^{-5} \mathrm{M}\right)$, or AG490 $\left(5 \times 10^{-5} \mathrm{M}\right)$ was added to the cells, followed by treatment with insulin $\left(10^{-5} \mathrm{M}\right)$. Finally, $20 \mu \mathrm{l}$ of $5 \mathrm{mg} / \mathrm{ml}$ MTT solution was added to each well and incubated for $4 \mathrm{~h}$. The supernatants were aspirated, and the formazan crystals in each well were dissolved in $150 \mu$ l dimethyl sulfoxide. Cell proliferation was assessed by measuring the absorbance at $490 \mathrm{~nm}$ using a microplate reader (DTX800; Beckman Coulter, Brea, CA, USA).

For cell cycle analysis by flow cytometry, RASMCs were seeded in 6-well culture plates ( $1 \times 10^{5}$ cells/well). After $24 \mathrm{~h}$, the medium was replaced with DMEM containing $1 \%$ FBS to render the cells quiescent for $24 \mathrm{~h}$. Then, RASMCs were pre-treated with RBP4 (1 or $4 \mu \mathrm{g} / \mathrm{ml})$ for $1 \mathrm{~h}$, or PD098059 $\left(5 \times 10^{-5} \mathrm{M}\right) / \mathrm{AG} 490\left(5 \times 10^{-5} \mathrm{M}\right)$ for $10 \mathrm{~min}$, followed by treatment with insulin $\left(10^{-5} \mathrm{M}\right)$ for $24 \mathrm{~h}$. After $24 \mathrm{~h}$, cells were trypsinized and washed with phosphate-buffered saline (PBS) twice before fixing in ice-cold $70 \%$ ethanol at $4^{\circ} \mathrm{C}$ overnight. After removing ethanol by centrifugation, cells were washed with PBS and treated, for $20 \mathrm{~min}$ in the dark, with $50 \mu \mathrm{g} / \mathrm{ml}$ propidium iodide solution (Sigma-Aldrich) combined with $100 \mu \mathrm{g} / \mathrm{ml}$ DNase-free RNase, $0.1 \%$ Triton X-100 and $0.1 \mathrm{mM}$ EDTA in PBS. After washing with PBS, propidium iodide-stained cells were subjected to cell cycle analysis using a FACScan flow cytometer (Becton Dickinson, Mountain View, CA, USA) and the FlowJo 7.1.0 software (Tree Star Inc., Ashland, OR, USA). At least 10,000 cells were counted for each sample. Data are presented as the percentage of cells in a given subpopulation.

Western blotting. RASMCs were lysed in RIPA lysis buffer containing $0.1 \mathrm{M}$ phenylmethylsulfonyl fluoride. After centrifugation at $12,000 \mathrm{rpm}$ for $20 \mathrm{~min}$, the protein concentrations of the supernatants were determined with the bicinchoninic acid assay (Sigma-Aldrich). Equal amounts of protein were mixed with sodium dodecyl sulfate (SDS) buffer and incubated at $100^{\circ} \mathrm{C}$ for $5 \mathrm{~min}$ before loading. Then, equal amounts of total protein were loaded and separated on a $15 \%$ SDS polyacrylamide gel by electrophoresis at a constant $90-\mathrm{V}$ voltage for $2.5 \mathrm{~h}$. Proteins were transferred under a standard module onto a polyvinylidene difluoride membrane (EMD Millipore, Billerica, MA, USA) for $45 \mathrm{~min}$. The membrane was blocked with a 5\% dry milk/Tris-buffered saline-Tween-20 (TBST) solution for $1 \mathrm{~h}$ at room temperature, and then probed with primary antibodies (anti-ERK1/2, -p-ERK1/2, -JAK2, -p-JAK2, -STAT3, -p-STAT3, dilution $1: 1,000$; - $\beta$-actin, 
$1: 3,000)$ in a $5 \%$ dry milk/TBST solution overnight at $4^{\circ} \mathrm{C}$. The membrane was rinsed several times with TBST buffer and then incubated with HRP-conjugated secondary antibodies $(1: 5,000)$ for $1 \mathrm{~h}$ at room temperature. Excess secondary antibody was removed by 3-4 washes in TBST buffer and the targeted protein bands were detected using an enhanced chemiluminescence (ECL) detection kit, followed by exposure of the membrane to an X-ray film. Protein bands were scanned and quantified using Image $\mathbf{J}$ software version 1.40 (National Institutes of Health, Bethesda, MD, USA). The quantified data for each protein were normalized to those for $\beta$-actin.

Statistical analysis. Data are expressed as means \pm SD and were statistically analyzed by Student's paired t-test for pairwise comparisons or ANOVA followed by Newman-Student-Keuls test for comparisons among multiple groups. $\mathrm{P}<0.05$ was considered to indicate a statistically significant difference. The SPSS 13.0 software was used for the analyses (IBM, Armonk, NY, USA).

\section{Results}

Proliferation of RAVSMCs induced by insulin. As previously mentioned, hyperinsulinemia is considered an independent risk factor for atherosclerosis and CVD. Insulin can promote VSMC proliferation and DNA synthesis, playing an important role in the formation of atherosclerosis. We therefore used insulin to stimulate proliferation in vitro. In line with results from a previous study (24), insulin induced proliferation of RASMCs in a concentration- and time-dependent manner, as shown by the increase in formazan absorbance (Fig. 1) and in the proportion of cells detected at the S and G2 phases (data not shown).

Expression of ERK1/2, p-ERK1/2, JAK2, p-JAK2, STAT3, $p$-STAT3 in RASMCs is induced by insulin. Since insulin induced proliferation of RASMCs in a concentration- and time-dependent manner, we used the most effective concentration $\left(10^{-5} \mathrm{M}\right)$ of insulin to further study the activation of signal transduction pathways related to cell proliferation. Insulin treatment enhanced the protein levels of ERK1/2, p-ERK1/2, JAK2, p-JAK2, STAT3, and p-STAT3 in a time-dependent manner, as shown by western blotting analysis (Fig. 2).

RBP4 enhances insulin-induced proliferation of RASMCs. RBP4 enhanced the insulin-induced proliferation of RASMCs, as shown by the increase in formazan absorbance and in the proportion of cells at the $\mathrm{S}+\mathrm{G} 2$ phases (Fig. 3A and B). The phosphorylation of ERK1/2, JAK2 and STAT3 is an indicator of the activation of the MAPK and the JAK/STAT signal transduction pathways. Notably, the expression of p-ERK and p-JAK2 that was induced by insulin was further enhanced by RBP4 treatment, while that of p-STAT3 remained unchanged (Fig. 3C).

Involvement of ERK1/2 and JAK2/STAT3 pathways in the enhancement of RASMC proliferation by RBP4. To determine whether the ERK1/2 and/or the JAK2/STAT3 pathway are involved in the enhancement of insulin-induced cell proliferation caused by RBP4, PD98059 (the specific ERK1/2 inhibitor)
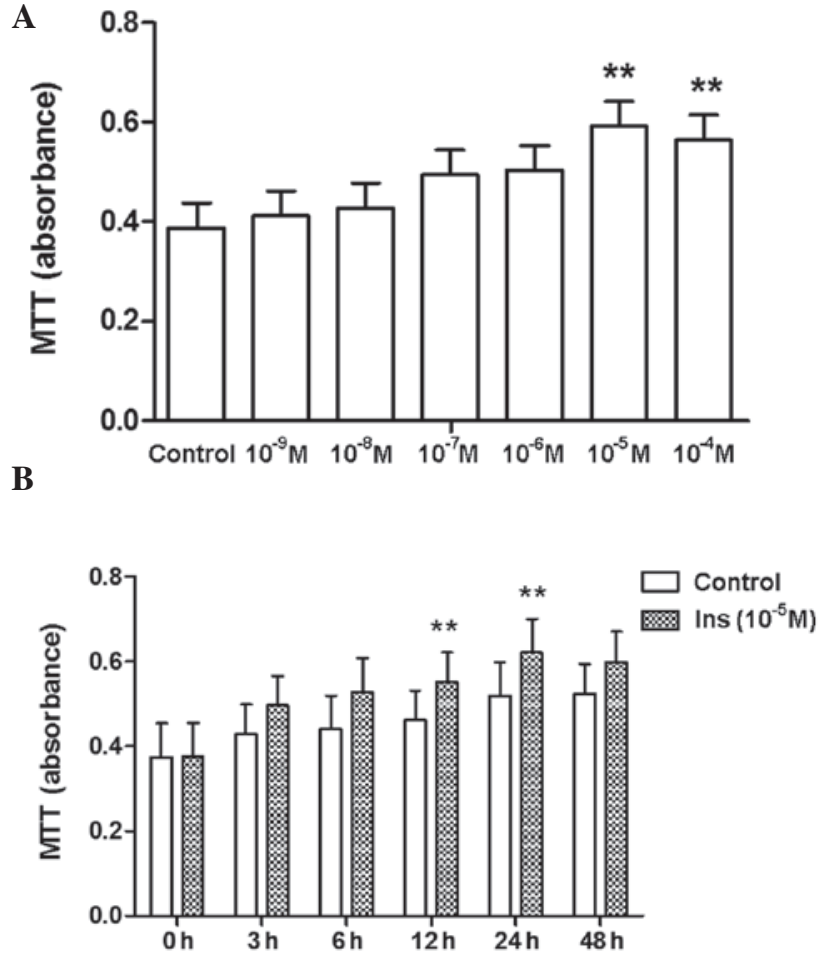

Figure 1. Proliferation of rat aortic smooth muscle cells (RASMCs) induced by insulin is (A) concentration-dependent and (B) time-dependent, with a peak observed at $24 \mathrm{~h}$. Proliferation was determined using the MTT assay. Data come from 8-10 independent experiments. ${ }^{* *} \mathrm{P}<0.01 \mathrm{vs}$. control $(0 \mathrm{~h} / 0 \mathrm{M})$.

and AG490 (the specific JAK2 inhibitor) were used. As shown by the MTT assay and flow cytometry, pre-treatment of cells with PD98059 $\left(5 \times 10^{-5} \mathrm{M}\right)$ significantly $(\mathrm{P}<0.01)$ inhibited proliferation of RASMCs, while pre-treatment with AG490 $\left(5 \times 10^{-5} \mathrm{M}\right)$ had no effect on proliferation (Fig. 4).

\section{Discussion}

The present study examined the effect of RBP4 on insulin-induced proliferation of RASMCs. The main findings are the following: i) insulin induced proliferation of RASMCs via the MAPK and JAK2/STAT3 pathways; ii) RBP4 enhanced insulin-induced proliferation of RASMCs and iii) RBP4 enhanced insulin-induced proliferation of RASMCs via the MAPK, but not the JAK2/STAT3 pathway. Collectively, these findings indicate that RBP4 may play an important role in the mediation of signals related to proliferation of VSMCs induced by insulin, which suggests that RBP4 may contribute to vascular remodeling in hyperinsulinemia.

Since the first study of Yang et al (3) on RBP4 effects in mice, related studies on RBP4 and insulin resistance, obesity, type 2 diabetes, and CHD have provided contradictory results. Mahmoudi et al (11) did not find a significant difference in the RBP4 level between a non-diabetic population with CHD and healthy controls. Mallat et al (12) attempted to prove that RBP4 can be used as a predictor of CHD. The authors studied 1,036 patients with CHD in a period of six years, and found that the risk of CHD increased in cases of increased RBP4 level. However, following adjustment of the data for other CHD risk factors, the positive correlation between the RBP4 level and the risk of heart disease proved not to be statistically 

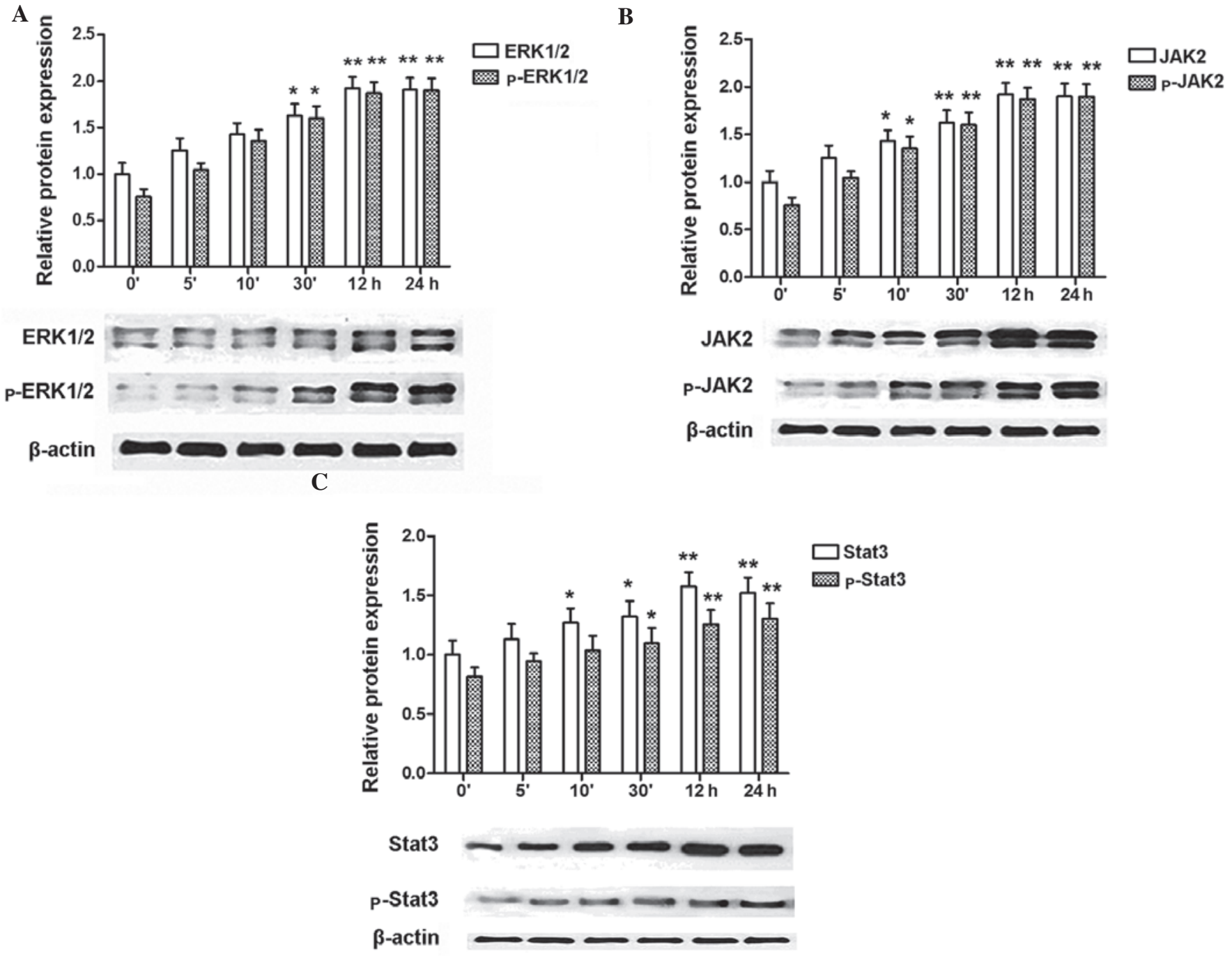

Figure 2. Expression of ERK2, p-ERK2, JAK2, p-JAK2, STAT3, p-STAT3 in rat aortic smooth muscle cells (RASMCs) induced by insulin. (A) Insulin induces the expression of ERK1/2, p-ERK1/2 in a time-dependent manner, with the maximum level of both proteins detected at $24 \mathrm{~h}$. (B) Insulin induces the expression of JAK2, p-JAK2 in a time-dependent manner, with the maximum level of JAK2 detected at $12 \mathrm{~h}$, and of p-JAK2 at $24 \mathrm{~h}$. (C) Insulin induces the expression of STAT3, p-STAT3 in a time-dependent manner, with the maximum level of STAT3 detected at $12 \mathrm{~h}$, and of p-STAT3 at $24 \mathrm{~h}$. Blots are representative of three independent experiments. ${ }^{*} \mathrm{P}<0.05,{ }^{* *} \mathrm{P}<0.01$ vs. control ( 0 ' without insulin).

significant, thereby suggesting that RBP4 may not be a robust predictor of CHD. However, there are studies that showed that RBP4 positively and significantly correlates to carotid intima-media thickness, which is an atherosclerosis indicator, and negatively correlates to flow-mediated dilatation $(25,26)$. Independent correlations between RBP4 and the low-density lipoprotein or the oxidized low-density lipoprotein have also been reported $(27,28)$. In addition, Cabré et al (29) showed that the RBP4 level is significantly higher in atherosclerotic patients with primary type 2 diabetes mellitus than in those without atherosclerosis. Overall, a potential correlation between RBP4 and atherosclerosis and CHD can not be unequivocally claimed. Atherosclerosis is the basic pathogenetic cause of CHD, while abnormal proliferation and migration of VSMCs is one of the most common causes of atherosclerosis, vascular restenosis and other CVDs.

Binding of insulin to insulin receptors (InsR) in the target organs and tissues activates the MAPK pathway through the Grb2/SOS and RAS proteins, thereby regulating gene transcription to promote cell growth and proliferation. In IR, even when pancreatic $\beta$ cells show a good function, compensatory hyperinsulinemia occurs and promotes insulin-induced proliferation of VSMCs via the SHC/Raf/MAPK pathway; in these conditions, hyperinsulinemia accelerates arterial atherosclerosis.

In agreement with a previous study (24), we showed that insulin induces proliferation of RASMCs in a concentration-dependent manner, with a $10^{-5} \mathrm{M}$ concentration exerting the strongest effect. We further showed that insulin induces expression of ERK1/2 and p-ERK1/2 in a time-dependent manner, and that this effect is the strongest at $24 \mathrm{~h}$ of treatment. The present and previous studies overall confirm that treatment with high concentrations of insulin stimulates RASMC proliferation through activation of MAPKs. Notably, we also observed a time-dependent stimulation of the expression of JAK, p-JAK, STAT3 and p-STAT3 by high concentrations of insulin in RASMCs. This result strongly suggests that the JAK/STAT cell proliferation signal transduction pathway is also regulated by high concentrations of insulin. Therefore, JAK/STAT pathways not only mediate 
A

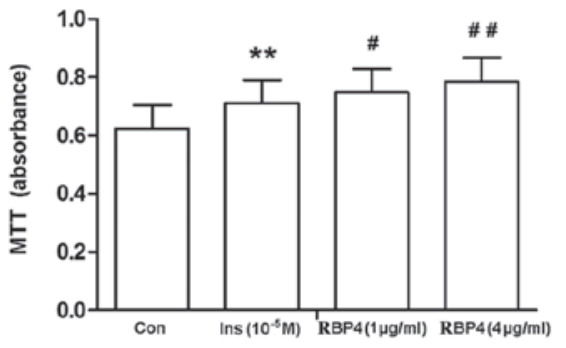

C
B

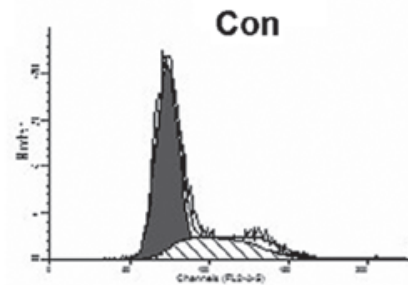

+RBP4(L)
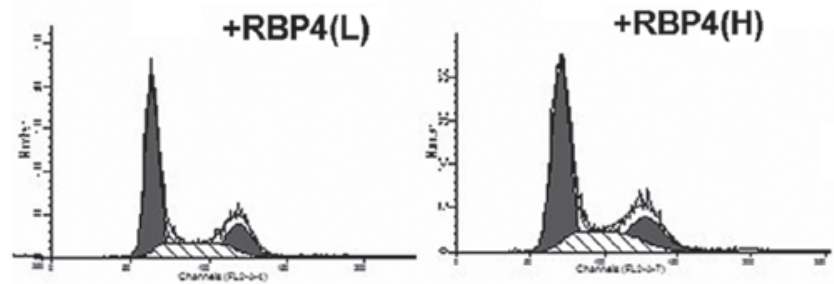

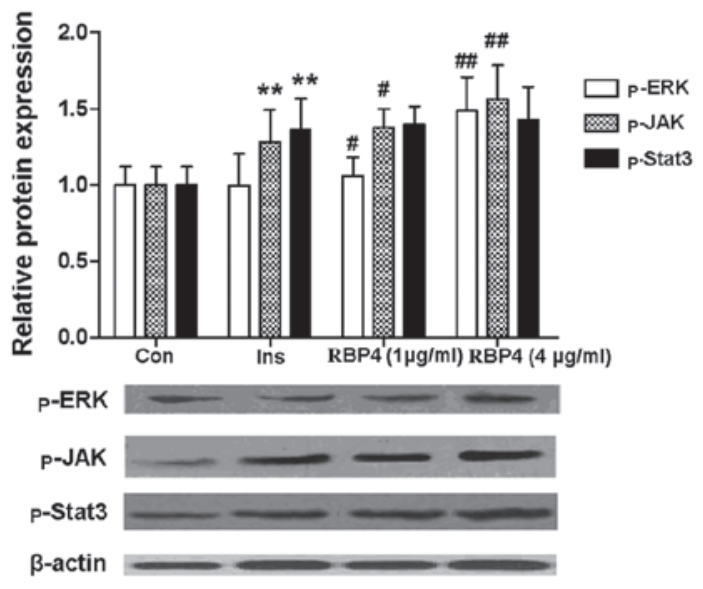

Figure 3. Retinol binding protein 4 (RBP4) increases insulin-induced proliferation of rat aortic smooth muscle cells (RASMCs), as determined by (A) the MTT assay and (B) flow cytometry. (C) RBP4 increases the protein level of p-ERK and p-JAK, but not that of p-STAT3. The blot is representative of three independent experiments. ${ }^{* *} \mathrm{P}<0.01$ vs. Con; ${ }^{\#} \mathrm{P}<0.05,{ }^{\# \#} \mathrm{P}<0.01$ vs. Ins. Con, untreated cells; Ins, cells treated with $10^{-5} \mathrm{M}$ insulin for $24 \mathrm{~h}$; $+\mathrm{RBP} 4(\mathrm{~L})$, cells pre-treated with RBP4 $(1 \mu \mathrm{g} / \mathrm{ml})$ for $1 \mathrm{~h}$ prior to treatment with insulin; +RBP4(H), cells pre-treated with $\mathrm{RBP} 4(4 \mu \mathrm{g} / \mathrm{ml})$ for $1 \mathrm{~h}$ prior to treatment with insulin. Data come from 8-10 independent experiments.

$\mathbf{A}$

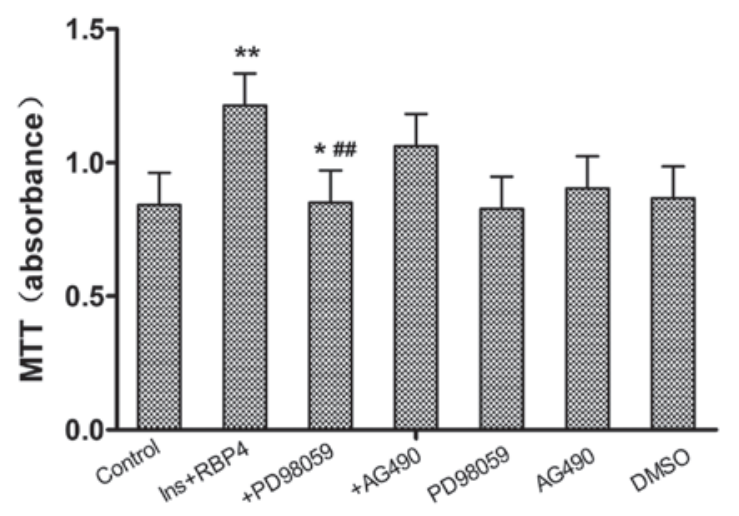

B

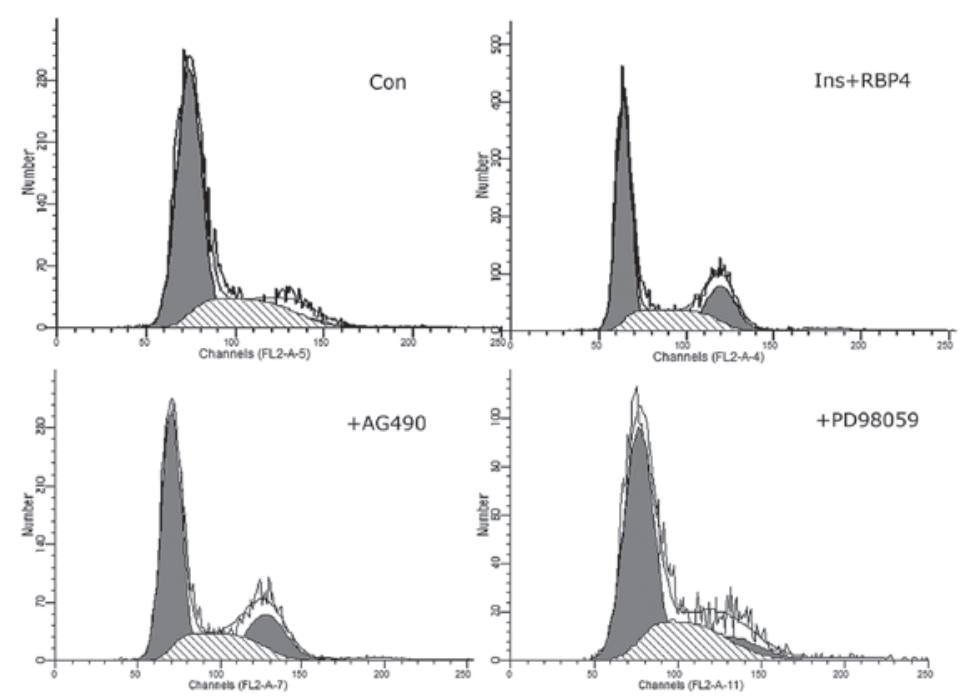

Figure 4. Involvement of the ERK1/2 and JAK2/STAT3 pathways in retinol binding protein 4 (RBP4)-mediated enhancement of rat aortic smooth muscle cell (RASMC) proliferation. (A) Proliferation of RASMCs measured by the MTT assay. RBP4-induced proliferation of RASMCs is inhibited in the presence of the JAK1/2 inhibitor PD98059 $\left(5 \times 10^{-5} \mathrm{M}\right)$ but not of the JAK2 inhibitor AG490 $\left(5 \times 10^{-5} \mathrm{M}\right)$. Data come from 3-8 independent experiments. "P<0.05, ${ }^{* *} \mathrm{P}<0.01$ vs. Con; ${ }^{\# \#} \mathrm{P}<0.01$ vs. Ins $\left(10^{-5} \mathrm{M}\right)+\mathrm{RBP} 4(4 \mu \mathrm{g} / \mathrm{ml})$. (B) Cell cycle analysis by flow cytometry. Control, untreated cells; Ins + RBP4, cells treated with $10^{-5} \mathrm{M}$ Ins + RBP4 $(4 \mu \mathrm{g} / \mathrm{ml})$ for $24 \mathrm{~h}$; +PD98059, cells pre-treated with PD98059 $\left(5 \times 10^{-5} \mathrm{M}\right)$ for 10 min prior to treatment with insulin and RBP4; +AG490, cells pretreated with AG490 $\left(5 \times 10^{-5} \mathrm{M}\right)$ for 10 min prior to treatment with insulin and RBP4; DMSO, wild-type cells treated with 0.1\% DMSO (PD98059 isovolumetric). 
proliferation of VSMCs induced by IL-6 (19), platelet-derived growth factor BB (30) and IL-18 (31), but may also have a role in hyperinsulinism-induced atherosclerosis.

In the present study, RASMCs were pre-incubated with RBP4 (1 or $4 \mu \mathrm{g} / \mathrm{ml}$ ) for $1 \mathrm{~h}$ prior to treatment with $10^{-5} \mathrm{M}$ insulin, and these experiments demonstrated that RBP4 significantly increases the ability of insulin to induce smooth muscle cell proliferation. The percentage of RBP4-treated cells that were detected at the $\mathrm{S}$ and $\mathrm{G} 2$ phases was considerably higher than that of the control cells. This study also found that RBP4 significantly enhances the insulin-induced level of p-ERK and p-JAK proteins, from which we can infer that the activation (phosphorylation) of ERK and JAK is significantly enhanced. No significant effect on STAT3 phosphorylation was observed under these conditions, thus we conclude that RBP4 enhances insulin-induced smooth muscle cell proliferation via the MAPK pathway. Pre-treatment of RASMCs with the ERK1/2 inhibitor PD98059 effectively inhibited the observed effects of RBP4, including cell cycle changes. However, treatment with the JAK inhibitor AG490 had no significant effect on RBP4-induced cell proliferation, and cell cycle distribution did not change. These findings argue for the involvement of the MAPK pathway in the promotion of the insulin-induced proliferation of RASMCs by RBP4.

Binding of insulin to the insulin receptor (InsR) mediates, via a number of signal transduction pathways, a variety of physiological effects in the target organs and tissues. There are at least two insulin-related signal transduction pathways: one is the phosphatidylinositide 3 kinase (PI-3K) pathway, which is activated by IRS; the second is the MAPK pathway, which is activated via the Grb2/SOS and RAS proteins. A high level of plasma RBP4 can enhance insulin resistance through inhibition of IRS-1 and activation of phosphatidylinositol 3-kinase (PI3-K) in skeletal muscles (3). In agreement with a study (22) reporting that RBP4 reduces insulin-induced phosphorylation of IRS-1 and ERK1/2 in human adipose tissue, Takebayashi et al (23) found that RBP4 increases the production of $\mathrm{NO}$ by stimulating part of the PI3K/Akt/eNOS pathway in vascular endothelial cells, and leads to vasodilation through inhibition of phosphorylation of ERK1/2 and insulin-induced secretion of endothelin. However, in the present study, RBP4 was shown to enhance phosphorylation of ERK1/2 in RASMCs, thereby promoting the proliferation of smooth muscle cells, and this effect was attenuated by the specific inhibitor of ERK1/2 PD98059. In target tissues and organs of individuals with obesity and type 2 diabetes, the IRS/PI-3K pathway is impaired, but the Shc/Raf/MAPK pathway remains intact, and is even stimulated (18). This 'selective insulin resistance' phenomenon mitigates insulin metabolic regulation, including its antagonistic effect in atherosclerosis. RBP4 can inhibit phosphorylation of IRS-1 $(3,22)$, then promote selective insulin resistance to enhance insulin-induced proliferation of vascular smooth muscle cells, and synthesis of collagen and growth factors.

In conclusion, the present study showed that insulin induces proliferation of RASMCs in a concentration- and time-dependent manner via the MAPK and JAK2/STAT3 pathways. In addition, we report, for the first time to the best of our knowledge, that RBP4 enhances RASMC proliferation induced by insulin via activation of the MAPK signaling pathway. Since this is a novel finding, additional research is needed to confirm it and further investigate the underlying mechanisms. The results from the present and previous studies indicate that RBP4 has a prominent role as a modulator of atherosclerosis in hyperinsulinemia, and may contribute to a better understanding of the numerous unexpected aspects of CVDs.

\section{References}

1. Al-Harithy RN and Al-Ghamdi S: Serum resistin, adiposity and insulin resistance in Saudi women with type 2 diabetes mellitus. Ann Saudi Med 25: 283-287, 2005.

2. Bauche IB, Ait El Mkadem S, Rezsohazy R, Funahashi T, Maeda N, Miranda LM and Brichard SM: Adiponectin downregulates its own production and the expression of its AdipoR2 receptor in transgenic mice. Biochem Biophys Res Commun 345: 1414-1424, 2006.

3. Yang, Q, Graham TE, Mody N, Preitner F, Peroni OD, Zabolotny JM, Kotani K, Quadro L and Kahn BB: Serum retinol binding protein 4 contributes to insulin resistance in obesity and type 2 diabetes. Nature 436: 356-362, 2005

4. Graham TE, Yang, Q, Bluher M, Hammarstedt A, Ciaraldi TP Henry RR, Wason CJ, Oberbach A, Jansson P, Smith U and Kahn BB: Retinol-binding protein 4 and insulin resistance in lean, obese, and diabetic subjects. N Engl J Med 354: 2552-2563, 2006.

5. Stefan N, Hennige AM, Staiger H, Machann J, Schick F, Schleicher E, Fritsche A and Häring HU: High circulating retinol-binding protein 4 is associated with elevated liver fat but not with total, subcutaneous, visceral, or intramyocellular fat in humans. Diabetes Care 30: 1173-1178, 2007.

6. Cho YM, Youn BS, Lee H, Lee N, Min SS, Kwak SH, Lee HK and Park KS: Plasma retinol-binding protein-4 concentrations are elevated in human subjects with impaired glucose tolerance and type 2 diabetes. Diabetes Care 29: 2457-2461, 2006.

7. Ribel-Madsen R, Friedrichsen M, Vaag A and Poulsen P: Retinol-binding protein 4 in twins: regulatory mechanisms and impact of circulating and tissue expression levels on insulin secretion and action. Diabetes 58: 54-60, 2009.

8. Klöting N, Graham TE, Berndt J, Kralisch S, Kovacs P, Wason CJ, Fasshauer M, Schön MR, Stumvoll M, Blüher M and Kahn BB: Serum retinol-binding protein is more highly expressed in visceral than in subcutaneous adipose tissue and is a marker of intra-abdominal fat mass. Cell Metab 6: 79-87, 2007.

9. Despres JP, Lamarche B, Mauriege P, Cantin B, Dagenais GR, Moorjani S and Lupien PJ: Hyperinsulinemia as an independent risk factor for ischemic heart disease. N Engl J Med 334: 952-957, 1996.

10. Pepe MG, Ginzton NH, Lee PD, Hintz RL and Greenberg PL: Receptor binding and mitogenic effects of insulin and insulin-like growth factors I and II for human myeloid leukemic cells. J Cell Physiol 133: 219-227, 1987.

11. Faries, PL, Rohan DI, Wyers MC, Marin ML, Hollier LH, Quist WC and LoGerfo FW: Vascular smooth muscle cells derived from atherosclerotic human arteries exhibit greater adhesion, migration, and proliferation than venous cells. J Surg Res 104: 22-28, 2002.

12. Mahmoudi MJ, Mahmoudi M, Siassi F, Hedayat M, Pasalar P, Chamari M, Abolhassani H, Rezaei N and Saboor-Yaraghi AA: Circulating retinol-binding protein 4 concentrations in patients with coronary artery disease and patients with type 2 diabetes mellitus. Int J Diabetes Dev Ctries 32: 105-110, 2012.

13. Mallat Z, Simon T, Benessiano J, Clement K, Taleb S, Wareham NJ, Luben R, Khaw KT, Tedgui A and Boekholdt SM: Retinol-binding protein 4 and prediction of incident coronary events in healthy men and women. J Clin Endocrinol Metab 94: 255-260, 2009.

14. Matsumoto K, Miyake S, Yano M, Ueki Y, Yamaguchi Y, Akazawa $\mathrm{S}$ and Tominaga $\mathrm{Y}$ : Insulin resistance and arteriosclerosis obliterans in patients with NIDDM. Diabetes Care 20: 1738-1743, 1997.

15. Giannattasio $\mathrm{C}$ and Mancia G: Arterial distensibility in humans: modulating mechanisms, alterations in diseases and effects of treatment. J Hypertens 20: 1889-1899, 2002.

16. Page $C$ and Doubell AF: Mitogen-activated protein kinase (MAPK) in cardiac tissues. Mol Cell Biochem 157: 49-57, 1996.

17. Pessin JE and Saltiel AR: Signaling pathways in insulin action: molecular targets of insulin resistance. J Clin Invest 106: 165-169, 2000. 
18. Cusi K, Maezono K, Osman A, Pendergrass M, Patti ME, Pratipanawatr T, DeFronzo RA, Kahn CR and Mandarino LJ: Insulin resistance differentially affects the PI3-kinase- and MAP kinase-mediated signaling in human muscle. J Clin Invest 105: 311-320, 2000

19. Horvath CM: STAT proteins and transcriptional responses to extracellular signals. Trends Biochem Sci 25: 496-502, 2000

20. Watanabe S, Mu W, Kahn A, Jing N, Li JH, Lan HY, Nakagawa T, Ohashi R and Johnson RJ: Role of JAK/STAT pathway in IL-6-induced activation of vascular smooth muscle cells. Am J Nephrol 24: 387-392, 2004.

21. Guo F, Zarella $\mathrm{C}$ and Wagner WD: STAT4 and the proliferation of artery smooth muscle cells in atherosclerosis. Exp Mol Pathol 81: 15-22, 2006.

22. Ost A, Danielsson A, Liden M, Eriksson U, Nystrom FH and Stralfors P: Retinol-binding protein-4 attenuates insulin-induced phosphorylation of IRS1 and ERK1/2 in primary human adipocytes. FASEB J 21: 3696-3704, 2007.

23. Takebayashi K, Sohma R, Aso Y and Inukai T: Effects of retinol binding protein- 4 on vascular endothelial cells. Biochem Biophys Res Commun 408: 58-64, 2011.

24. Wang CC, Gurevich I and Draznin B: Insulin affects vascular smooth muscle cell phenotype and migration via distinct signaling pathways. Diabetes 52: 2562-2569, 2003.

25. Ingelsson E, Sundström J, Melhus H, Michaëlsson K, Berne C, Vasan RS, Risérus U, Blomhoff R, Lind L and Ärnlöv J: Circulating retinol-binding protein 4 , cardiovascular risk factors and prevalent cardiovascular disease in elderly. Atherosclerosis 206: 239-244, 2009.
26. Bobbert T, Raila J, Schwarz F, Mai K, Henze A, Pfeiffer AF, Schweigert FJ and Spranger J: Relation between retinol, retinol-binding protein 4 , transthyretin and carotid intima media thickness. Atherosclerosis 213: 549-551, 2010.

27. Wu J, Shi YH, Niu DM, Li HQ, Zhang CN and Wang JJ: Association among retinol-binding protein 4, small dense LDL cholesterol and oxidized LDL levels in dyslipidemia subjects. Clin Biochem 45: 619-622, 2012.

28. von Eynatten M, Lepper PM, Liu D, Lang K, Baumann M, Nawroth PP, Bierhaus A, Dugi KA, Heemann U, Allolio B and Humpert PM: Retinol-binding protein 4 is associated with components of the metabolic syndrome, but not with insulin resistance, in men with type 2 diabetes or coronary artery disease. Diabetologia 50: 1930-1937, 2007.

29. Cabré A, Lázaro I, Girona J, Manzanares J, Marimón F, Plana N, Heras M and Masana L: Retinol-binding protein 4 as a plasma biomarker of renal dysfunction and cardiovascular disease in type 2 diabetes. J Intern Med 262: 496-503, 2007.

30. Neeli I, Liu ZM, Dronadula N, Ma ZA and Rao GN: An essential role of the Jak-2/STAT-3/cytosolic phospholipase A(2) axis in platelet-derived growth factor BB-induced vascular smooth muscle cell motility. J Biol Chem 279: 46122-46128, 2004.

31. Sahar S, Dwarakanath RS, Reddy MA, Lanting L, Todorov I and Natarajan R: Angiotensin II enhances interleukin-18 mediated inflammatory gene expression in vascular smooth muscle cells: a novel cross-talk in the pathogenesis of atherosclerosis. Circ Res 96: 1064-1071, 2005. 